\title{
Personalised food: how personal is it?
}

\author{
Dilip Ghosh
}

Received: 20 July 2009/Accepted: 3 August 2009/Published online: 11 September 2009

(C) Springer-Verlag 2009

\begin{abstract}
Consumer goods became increasingly personalised, particularly during the last half of the 20th century. Foods and food products have been added a new flavour in this consumer trends with increasingly personalised values of convenience, cost, packaging, and taste. Now functional food industry is ready to take its next venture in a relatively new domain personalising health. Whether the goal of matching foods to individual genotypes to improve the health of those individuals can be attained, and personalised nutrigenomic foods enter the world's food markets, depends on numerous hurdles being overcome: some scientific in nature, some technical and others related to consumer, market or ethical issues. Public adoption of new technologies is an important determinant for their success. Many of the drivers behind the trend in personalisation of food are now known, particularly ethical, legal and social issues (ELSI) are the major drivers. Future development in the field of nutrigenomics undoubtedly will place its seemingly huge potential in better perspective. Thus, the agriculture and food enterprise has an extraordinary opportunity to link individuals with foods that are personalised for their health.
\end{abstract}

Keywords Consumer - Functional food · Nutrition . Nutrigenomics $\cdot$ Personalised food

This article belongs to a special issue on the 4th International Niigata Symposium on Diet and Health, 29-30 November 2008.

D. Ghosh ( $\square)$

Nutriconnect, Sydney, NSW 2154, Australia

e-mail: dilipghosh@nutriconnect.com.au

\section{Introduction}

Human health is intrinsically related to food and medicine and has a long history of sustainable use for well-being [18]. With the development of new 'omics' technologies and introduction of personalised food concept, the boundary between food and medicine is blurred everyday [12]. Traditional medical practices, for example, Chinese medicine and Ayurveda (Indian traditional medicine), have utilised the medicinal properties of food and are still practiced today as alternative therapies. Traditional herbal medicine formulas are not designed to treat symptoms of a specific illness; rather, they are tailored specifically to the individual according to the complex principles of oriental medicine [20, 26].

In a complex relationship of food, illness and the body, food may be the cause and also a cure of illness. As the emerging science of nutrigenomics begins to make market penetration through the process of designing a framework for personalised nutrition, food and nutrition professionals may find themselves overwhelmed by the abundance of new information [3, 19]. The hype of personalisation has increased consumer expectations as well as the responsibility of manufacturers and regulatory bodies $[5,13,14]$. Optimisation of health through genomics and continual market penetration of nutrigenetics and nutrigenomics products have made health an increasingly complex issue in the scientific, legal and common understanding [2].

In this review, emerging paradigms of nutritional genomics are discussed as they relate to the functional food market. Emphasis is given on the consumer acceptance and market penetration of the product based on this concept to improve human nutrition and health and thereby deliver societal and economic benefits. 


\section{Nutrigenomics from nutrition perspective}

The concept of the nutrition and health link is only appreciated if uncoupled from a biomedical approach, and linked to the awareness that multiple minor changes in metabolism contribute to chronic nutrition-related disorders such as obesity, type- 2 diabetes, cardiovascular disorders, osteoporosis, chronic inflammatory syndromes and so on $[16,23,25]$. One of the key issues here is, of course, that we are not dealing with 'single exposure-single time point' type of studies, but that multiple dosing of complex mixtures of bioactive compounds, mostly at the low doses need to be studied. In reality, the complexity of mixtures (real life nutritional toxicology) was mostly neglected.

With the emerging 'omics' technologies, the aspect of what can be observed in terms of biological effects will surely get a new meaning. Analytical tools in transcriptomics, proteomics and metabolomics will gain in sensitivity, not only because classical detection limits are lowered, but much more because multiple minor changes taken together in new bioinformatics approaches together create a new sense of sensitivity $[10,15]$.

\section{Drivers in functional foods}

There are a number of drivers for functional foods, with trends emerging in market analyses. New nutrition business, for example, publishes "10 Key Trends in Functional Foods" on a regular basis [17]. Although 'nutrigenomic' foods have yet to be mentioned specifically as such, many of the 2008 trends described in the marketing sense refer directly or indirectly to "personalisation" aspects. One recent market analysis on functional foods [4] noted that although the industry is already crowded, there appears to be some splintering into subcategories based on the consumer target markets (niche markets). Many of the drivers behind this trend in personalisation of food can be seen to come from the demand of changing demographics and social trends (more "singles" and childless couples), increasing scientific research and clinical evidence for the efficacy of functional foods, consumers awareness for "natural" alternatives and alternative medicine (the move from health care to selfcare), increased nutrition-oriented marketing activity, etc. [24]. Some experts advocated that "the application of nutrigenomics in the form of personalised foods hold the potential to shift the food market from a technology push into a consumer pull system, where the consumer's preference for optimal health is a major driver for food choice and food production" [11]. Ethical legal and social issues are adding a new dimension in functionalised food development as a future driver.

\section{Commercial application of nutrigenomics}

The 'biohype' around the nutrigenomics foods and nutrigenetics tests are imminent and unavoidable, particularly in the early stages of evolution of a new idea. In reality, 'biohype' is already taking place through the unregulated marketing of nutrigenomics tests to the public [13, 14]. Although it is yet to be determined how the science of nutritional genomics will develop in the future, but raising concern over ethical, legal and social issues (ELSIs) that may remember the backlash of genetically modified foods introduction in market. Five areas have been identified by international experts [6] in the context of both basic nutrigenomics research and its clinical and commercial uses: (1) health claims benefits arising from nutrigenomics, (2) managing nutrigenomics information, (3) delivery methods of nutrigenomics services, (4) nutrigenomics products and (5) equitable accessibility to nutrigenomics. Hence, it is important to elevate the depth of debate to understand and management of this 'biohype' on dietgene interactions using evidence-based research methodologies $[7,8]$.

\section{Consumer acceptance of personalised food with genomic flavour}

Nutrigenomics is an emerging technology in the health maintenance and promotion area represented by personalised food products and services. Besides, advancing the fundamental understanding of diet-disease relationships, nutrigenomics could provide opportunities for the development of food products or dietary advice tailored to the nutritional needs of specific groups of consumers, or even individuals. In all situations, the consumer's preference for optimal health is a major driver for food choice, and food production [11]. It is becoming increasingly difficult to convince the consumer outside the America of the benefits of new products and procedures that are somehow connected with genes and/or cloning. Resistance towards these techniques has been strong and appears to be growing. They are ready to accept the product with "personalised" label rather than "nutrigenomics". Moreover, consumers prefer communication on nutrigenomics and personalised nutrition by expert stakeholders such as nutritional scientists [21, 22]. Eurobarometer survey in 2002 involving 16,500 subjects in the member states of the European Union has demonstrated the majority of respondents supported genetic testing for disease [9]. To date, only one study has been published that probe differences between genetic testing for a disease and genotyping to predict the probability of response to some dietary intervention [1]. 


\section{Discussion}

Nutrigenomics provides a platform for food product development that follows earlier developments in functional foods, or foods that somehow are 'better for you'. The value add now moves on to not just components with newly discovered functional properties, but also how these functional properties may interact with the genetic environment of the consumer. It is the ultimate environmental influence on genetic expression, as food becomes the individual. Healthcare practice and food product development will move on regardless and it is the partnership of science and practice that will enable a smooth uptake and translation of new knowledge in the field as it emerges. Steps in this direction, however, must be taken with caution and great care. There are ethical issues to consider in terms of consumer confidentiality and rights to be fully informed. It will be increasingly necessary to communicate the extent of the lack of knowledge as it is the extent of knowledge in the area to maintain trust, build effective partnerships (including with consumers) and, and most importantly, to do no harm.

The convincing evidence about the interaction of nutrients, genetic variations and health implications is still uncertain. We see this as a future, the nutrigenomics concept makes sense, but we are still far from personalised nutrition. "With nutrigenomics, this is looking to the horizon. There are a lot of knowledge gaps, particularly in terms of what the research is saying and what is actually possible", the remark of Dr. Andrew Shao, of US Council for Responsible Nutrition is the best possible current scenario of this great science.

Conflict of interest statement There is no conflict of interest to disclose.

\section{References}

1. Arkadianos I, Valdes AM, Marinos E, Florou A, Gill RD, Grimaldi KA (2007) Improved weight management using genetic information to personalize a calorie controlled diet. Nutr J 6:29

2. Bhardwaj M (2007) From farm to pharma: public health challenges of nutrigenomics. Personalized Med 4:423-430

3. Brown L, van der Ouderaa F (2007) Nutritional genomics: food industry applications from farm to fork. Br J Nutr 97:1027-1035

4. Business Insights (2006) http://www.marketresearch.com/product/ display.asp?productid=1397897\&SID=34275478-392462003-3596 28325

5. Castle D, Ries NM (2007) Ethical, legal and social issues in nutrigenomics: the challenges of regulating service delivery and building health professional capacity. Mutat Res Fundam Mol Mech Mutagen 622:138-143
6. Castle D, Cline C, Daar A, Tsamis C, Singer PA (2006) In: Kaput J, Rodriguez RL (eds) Nutritional genomics: discovering the path to personalized nutrition. Wiley Interscience, London, pp 419-434

7. Debusk R (2009) Diet-related disease, nutritional genomics, and food and nutrition professionals. $\mathrm{J}$ Am Diet Assoc. doi: 10.1016/j.jada.2008.11.037

8. Ferguson LR (2009) Nutrigenomics approaches to functional foods. J Am Diet Assoc 109:452-458

9. Gaskell G, Allum N, Stares S (2003) Europeans and Biotechnology in 2002. DG Research, Brussels

10. German JB, Roberts MA, Watkins SM (2003) Genomics and metabolomics as markers for the interaction of diet and health: lessons from lipids. J Nutr 133:2078S-2083S

11. German JB, Yeretzian C, Watzke HJ (2004) Personalizing foods for health and preference. Food Technol 58:26-31

12. Ghosh D, Skinner M, Laing W (2007) Nutrigenomics and pharmacogenomics: synergies and differences. Eur J Clin Nutr 61:567-574

13. Ghosh D, Tapsell L (2008) Nutrigenomics: a genomic approach to human nutrition. In: Genomics: principles, applications and regulatory perspectives. CRC Press, USA, pp 337-344

14. Ghosh D (2009) Future perspectives of nutrigenomics foods: benefits vs. risks. Indian J Biochem Biophys 46:37-44

15. Joost HG, Gibney MJ, Cashman KD, Görman U, Hesketh JE, Mueller M, Ommen BV, Williams CM, Mathers JC (2007) Personalised nutrition: status and perspectives. Br J Nutr 98:26-31

16. Kris-Etherton PM, Hecker KD, Bonanome A, Coval SM, Binkoski AE, Hilpert KF, Griel AE, Etherton TD (2002) Bioactive compounds in foods: the role in the prevention of cardiovascular disease and cancer. Am J Med 113:71S-88S

17. Mellentin J (2009) Ten Key Trends in Food, Nutrition and Health 2008, New Nutrition Business (The Centre for Food and Health Studies, Crown House, 72 Hammersmith Road, London W14 8TH, UK, http://www.new-nutrition.com/10kt08.asp)

18. Müller M, Kersten S (2003) Nutrigenomics: goals and strategies. Nat Rev Genet 4:315-322

19. Pendersa B, Horstman K, Saris WHM, Vos R (2007) From individuals to groups: a review of the meaning of 'personalized' in nutrigenomics. Trends Food Sci Technol 18:333-338

20. Ravi Subbiah MT (2007) Nutrigenetics and nutraceuticals: the next wave riding on personalized medicine. Transl Res 149:55-61

21. Ronteltap A, van Trijp JCM, Renes RJ, Frewer FJ (2007) Consumer acceptance of technology-based food innovations: lessons for the future of nutrigenomics. Appetite 49:1-17

22. Ronteltap A, van Trijp JCM, Renes RJ (2009) Consumer acceptance of nutrigenomics-based personalised nutrition. Br J Nutr 101:132-144

23. Stewart TL, Ralston SH (2000) Review of genetic factors in the pathogenesis of osteoporosis. J Endocrinol 166:235-245

24. Sutton KH (2007) Considerations for the successful development and launch of personalised nutrigenomic foods. Mutat Res Fundam Mol Mech Mutagen 622:117-121

25. Ye SQ, Kwiterovich PO (2000) Influence of genetic polymorphisms on responsiveness to dietary fat and cholesterol. Am J Clin Nutr 72:1275-1845

26. You M, Guo-Zheng Li G-Z, Zeng X-Q, Ge L, Bi L, Huang S, Yang M-Q, Yang JY (2008) A personalized traditional Chinese medicine system in the case of Cai's gynecology. Int J Funct Inform Personalised Med 1:419-438 